\title{
A Validated Stability-Indicating HPLC Assay Method for Flucytosine in Bulk Drug
}

\author{
Milind Ubale \\ Post Graduate Department of Chemistry \\ Vasantrao Naik College, Aurangabad (MS) INDIA \\ Mahesh Shioorkar \\ Department of Chemistry \\ Vivekanand College, Aurangabad (MS) INDIA \\ Vilas Choudhari \\ Department of Chemistry \\ Yogeshwari College, Ambejogai (MS) INDIA
}

\begin{abstract}
An isocratic reversed phase stability-indicating high-performance liquid chromatographic (HPLC) assay method was developed and validated for quantitative determination of Flucytosine in bulk drugs. An isocratic, reversed phase HPLC method was developed to separate the drug from the degradation products, using a Water Nova Pack C18 $(250 \times 4.6) \mathrm{mm}, 5 \mu$ column and the mobile phase containing $1.0 \mathrm{gm}$ Sodium dihydrogen phosphate and 1.0 gm 1octaneSulfonic acid salt in $1000 \mathrm{ml}$ water filter and mixed. Prepare a homogenous mixture of buffer, methanol and acetonitrile (50:20:30,v/v/v). The detection was carried out at wavelength $264 \mathrm{~nm}$. The developed method was validated with respect to linearity, accuracy (recovery), precision, system suitability, selectivity, robustness prove the stability indicating ability of the method.
\end{abstract}

Keywords - HPLC, Flucytosin, Degradation, Chromatographic Column

\section{INTRODUCTION}

Flucytosine, or 5-fluorocytosine, a fluorinated pyrimidine analogue, is a synthetic antimycotic drug. It is structurally related to the cytostatic fluorouracil and to floxuridine. It is available in oral and in some countries also in inject able form. A common brand name is Ancobon. [1-4] Ancobon (Flucytosine), an antifungal agent, is available as 250mg and 500mg capsules for oral administration. Each capsule also contains corn starch, lactose and talc. Gelatin capsule shells contain parabens (butyl, methyl, propyl) and sodium propionate, with the following dye systems: 250-mg capsules, black iron oxide, FD\&C Blue No. 1, FD\&C Yellow No. 6, D\&C Yellow No. 10 and titanium dioxide; $500 \mathrm{mg}$ capsules - black iron oxide and titanium dioxide. Chemically, Flucytosine is 5-fluorocytosine, a fluorinated pyrimidine which is related to fluorouracil and floxuridine. [5-6]

Flucytosine is a water-soluble antifungal agent that is taken up by susceptible fungal cells via cytosine permease and subsequently converted to 5-fluorouracil by cytosine deaminase. 5-Fluorouacil inhibits the synthesis of fungal RNA and DNA by two mechanisms: Conversion of 5-fluorouracil to 5-fluorouridine triphosphate and incorporation into RNA, which causes miscoding, and Conversion of 5-fluorouracil into 5- fluorodeoxyuridine monophosphate, which prevents DNA synthesis by inhibiting thymidylate synthase. [7-10]

When Flucytosine is combined with amphotericin B, there is enhanced uptake of Flucytosine by fungal cells that are otherwise resistant to this agent. Flucytosine is used in combination with amphotericin B or fluconazole for enhanced activity against Candida and cryptococcal species that cause urinary-tract infections, pneumonia, fungemia, meningitis, and endocarditic. [11-12] 


\begin{tabular}{|l|ll|}
\hline & $\begin{array}{l}\text { Molecular formula } \\
\mathrm{C}_{4} \mathrm{H}_{4} \mathrm{FN}_{3} \mathrm{O}\end{array}$ \\
Molecular weight & 129.093 \\
IUPAC & 4-amino-5-fluoro-1,2-dihydropyrimidin-2-one \\
Nomenclature & off-white crystalline powder \\
Colour & Therapeutic Category & Antifungal agent. \\
\hline
\end{tabular}

Two published studies have examined the stability of flucytosine $10 \mathrm{mg} / \mathrm{mL}$ in extemporaneously prepared oral liquids [15].

A high-pressure liquid chromatographic method for the analysis of Flucytosine and furosemide concentrations in biological fluid is described [16]. The separations were carried out on a pellicular cation-exchange resin eluted with an ammonium phosphate buffer. Detection of elution peaks was by UV absorption at $280 \mathrm{~nm}$ and fluorescence monitoring. Advantages of the method are specificity, minimal pre-analysis sample workup, and small.

In continuation [17] of our previous work Present study involves development of RP-HPLC method using simple mobile phase which was sensitive and rapid for quantification Flucytosine in tablet samples as well as subsequent validation of developed method according to ICH guide lines. [18].

\section{Material and reagents}

\section{EXPERIMENTAL}

Flucytosine bulk drug was made available from Lupin Ltd. India (purity 99.8). Sodium dihydrogen phosphate, 1- octaneSulfonic acid was obtained from Qualigens fine chemicals, India Limited. Acetonitrile and methanol were obtained from Rankem laboratories, India. All chemicals and reagent were used as HPLC grades, Milli-Q-Water was used throughout the experiment.

\section{Chromatographic Conditions}

A chromatographic system (Systronic) consisting of quaternary solvent delivery pump, a degasser, an auto- injector, column oven and UV detector. The chromatographic column of $250 \mathrm{~mm}$ length and internal diameter of $4.6 \mathrm{~mm}$ filled with Octadecyl silane Water Nova Pack C18 $(250$ x 4.6) $\mathrm{mm}, 5 \mu$ stationary phase with particle size 5 micron and pore size $100 \mathrm{~A}^{\circ}$ was used. The instrumental settings were a flow of $1 \mathrm{ml} / \mathrm{min}$, the injection volume was $10 \mu l$. and wavelength $264 \mathrm{~nm}$.

\section{Mobile Phase}

The mobile phase containing 1.0gm Sodium dihydrogen phosphate and 1.0 gm 1-octane Sulfonic acid salt in 1000ml water filter and mixed. Prepare a homogenous mixture of buffer, methanol and acetonitrile (50:20:30, v/v/v).

Preparation of Standard stock solutions

Standard stock solutions of $500 \mathrm{ppm}$ of Flucytosine in acetonitrile and water (25:75) were prepared in volumetric flasks.

Sample solution

$500 \mathrm{ppm}$ of Flucytosine in $100 \mathrm{ml}$ calibrated flask containing acetonitrile and water mixture (25:75. The desired concentration for the drug was obtained by accurate dilution and the analysis was followed up as in the general analytical procedure $[18,19]$.

Selectivity

Selectivity is the ability of the method to assess unequivocally the analyte in the presence of components, which may be expected to be present. Typically, these might include degradants, matrix etc. The selectivity of the developed LC method for Flucytosine was carried out in the presence of its degradation products. Stress studies were performed for Flucytosine bulk drug to provide an indication of the stability indicating property and selectivity of the proposed method. Intentional degradation was attempted to stress condition exposing it with acid $(0.25 \mathrm{~N}$ Hydrochloric acid), alkali $(0.25 \mathrm{~N} \mathrm{NaOH})$ hydrogen peroxide $(10 \%)$ heat $\left(60^{\circ} \mathrm{C}\right)$ to evaluate the ability of the proposed method to separate Flucytosine from its degraded products. For heat study, study period was 3 days where as for acid, oxidation $48 \mathrm{hr}$ and for base 2 hour. Assay studies were carried out for stress samples against Flucytosin reference standard and the mass balance ( $\%$ assay $+\%$ sum of all impurities $+\%$ sum of all degraded products) was calculated. 
Optimization of chromatographic conditions

\section{RESULTS AND DISCUSSION}

The main target for the development of chromatographic method was to get the reliable method for the quantification of Flucytosine from bulk drug and which will be also applicable for the degradable products. Initially, we took the effort for the development of HPLC method quantification of standard Flucytosin from bulk. For this purpose, we have used Water nova pack C18(150X4.6)mm,5 $\mu$, Kromasil C18(150X4.6)mm,5 $\mu$, Inertsil ODS 3V C18(250X4.6)mm,5 $\mu$ and Kromasil C18(250X4.6)mm,5 $\mu$,Star ODS-II C18 (250X4.6)mm,5 $\mu$ and Grace Alpha C18 $(250 \mathrm{~mm} \times 4.6) \mathrm{mm}, 5 \mathrm{u}$ Out of these used HPLC column, Water Nova Pack C18 $(250 \mathrm{~mm} \times 4.6) \mathrm{mm}, 5 \mathrm{u}$ found to comparatively better and gave the graph with better gaussian shape at retention time $9.38 \mathrm{~min}$. To improve the shape and width of the graph, for the above columns different solvents and buffer taken for trials such as $0.1 \mathrm{M} \mathrm{KH}_{2} \mathrm{PO}_{4}$ and Acetonitrile $(60: 40, \mathrm{~V} / \mathrm{v})$ in these trials peak shape is not good, another trials 0.01M Ammonium acetate PH-5.9 and acetonitrile $(20: 80, \mathrm{v} / \mathrm{v})$ peak shape not found well, trials Acetonitrile and water $(80: 20, \mathrm{v} / \mathrm{v})$ column temperature $35^{\circ} \mathrm{C}$ peak shape not found good, trials $\mathrm{K}_{2} \mathrm{HPO}_{4}$, Methanol and water $(10: 70: 20, \mathrm{v} / \mathrm{v} / \mathrm{v})$ column temperature $35^{\circ} \mathrm{C}$, trials $1.0 \mathrm{gm} \mathrm{KH}_{2} \mathrm{PO}_{4}$ and $0.45 \mathrm{gm} 1$-Hexa sulphonic acid sodium salt make $p \mathrm{H}-3.5$ Ortho phosphoric acid and methanol(25:75, v/v) peak shape obtained but retention is not good, finally try for 2.0gm Sodium dihydrogen phosphate and $1.0 \mathrm{gm} \mathrm{1-octane} \mathrm{sulfonic} \mathrm{acid} \mathrm{salt} \mathrm{in} 1000 \mathrm{ml}$ water filter and mixed. Prepare a homogenous mixture of buffer, methanol and acetonitrile (50:20:30, v/v/v).

\section{Method Validation}

The validation of analytical procedures is based on the four most common types of analytical procedures: Identification tests, Quantitative tests for impurities' content, and Limit tests for the control of impurities, Quantitative tests of the active moiety in samples of drug substance or drug product or other selected components in the drug product.

In the present study the developed method was validated, as described below, for various parameters like linearity and range, accuracy, precision, ruggedness, system suitability, specificity, LOQ, and LOD.

\section{System suitability}

For system suitability studies, five replicate injections of acid, base and oxidative degraded solutions were used and the RSD of peak area ratio, resolutions, tailing factor and number of theoretical plates of the peak were calculated. The system suitability results are shown in Table $\mathbf{1 .}$

Table-1 System stability study.

\begin{tabular}{|c|c|c|}
\hline Working Standard & Wt. of Standard (mg) & Area \\
\hline Injection-1 & $\mathbf{4 8 . 1 2} \mathbf{~ m g}$ & $\mathbf{1 8 8 3 . 0 0}$ \\
\hline Injection-2 & ----- & 1883.00 \\
\hline Injection-3 & ---- & 1881.90 \\
\hline Injection-4 & ---- & 1884.62 \\
\hline Injection-5 & ----- & 1882.32 \\
\hline Injection-6 & ---- & 1882.69 \\
\hline AVG & ----- & 1882.57 \\
\hline SD & --- & 1.25 \\
\hline \%RSD & ----- & 0.07 \\
\hline
\end{tabular}

\section{Precision}

The precision of the method was studied by determining the concentrations of the drug Flucytosin in the tablet for six times [19]. The results of the precision study (Table 3) indicate the reliability of the method $(\operatorname{RSD} \%<2)$.

Table-2 System Precision

\begin{tabular}{|c|c|c|c|c|}
\hline Sample No. & Wt. of sample (mg) & Area & Assay (as such basis) & Assay (on dried basis) \\
\hline 1 & 49.00 & 1915.17 & 99.58 & 99.93 \\
\hline 2 & 49.69 & 1937.86 & 99.36 & 99.71 \\
\hline 3 & 50.00 & 1949.59 & 99.34 & 99.70 \\
\hline 4 & 53.89 & 2107.06 & 99.61 & 99.97 \\
\hline 5 & 49.12 & 1909.46 & 99.04 & 99.39 \\
\hline 6 & 48.15 & 1877.31 & 99.33 & 99.69 \\
\hline
\end{tabular}




\begin{tabular}{|c|c|c|c|c|}
\hline AVG & --- & --- & 99.37 & 99.73 \\
\hline SD & --- & --- & 0.21 & 0.21 \\
\hline \%RSD & --- & --- & 0.21 & 0.21 \\
\hline
\end{tabular}

Table-3 Intermediate system precision (Standard)

\begin{tabular}{|c|c|c|}
\hline Working Standard & Wt. of Standard (mg) & Area \\
\hline Injection-1 & $49.12 \mathrm{mg}$ & 1931342.00 \\
\hline Injection-2 & ----- & 1934304.00 \\
\hline Injection-3 & ----- & 1929631.00 \\
\hline Injection-4 & ---- & 1933176.00 \\
\hline Injection-5 & ---- & 1933807.00 \\
\hline Injection-6 & ---- & 1930941.00 \\
\hline AVG & ---- & 1932200.17 \\
\hline SD & ----- & 1837.54 \\
\hline \%RSD & ---- & 0.10 \\
\hline
\end{tabular}

Table-4 Intermediate system precision (Sample)

\begin{tabular}{|c|c|c|c|c|}
\hline Sample No. & Wt. of sample (mg) & Area & Assay (as such basis) & Assay (on dried basis) \\
\hline 1 & 49.45 & 1948339.00 & 99.83 & 100.19 \\
\hline 2 & 50.00 & 1970930.00 & 99.88 & 100.24 \\
\hline 3 & 50.35 & 1979507.00 & 99.62 & 99.98 \\
\hline 4 & 53.29 & 2099614.00 & 99.83 & 100.19 \\
\hline 5 & 49.12 & 1930371.00 & 99.58 & 99.94 \\
\hline 6 & 48.59 & 1913075.00 & 99.76 & 100.12 \\
\hline AVG & ---- & ---- & 99.75 & 100.11 \\
\hline SD & --- & --- & 0.13 & 0.13 \\
\hline$\%$ RSD & $-\ldots$ & $-\ldots$ & 0.13 & 0.13 \\
\hline
\end{tabular}

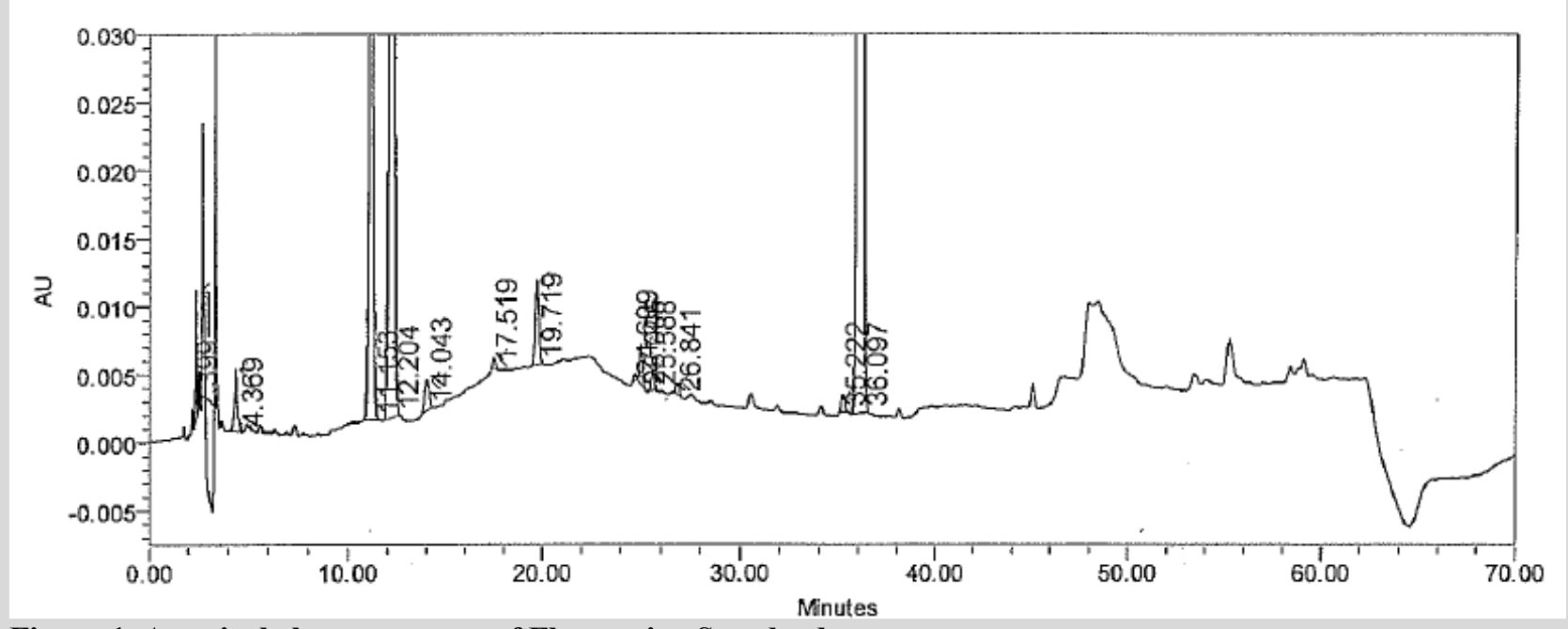

Figure 1. A typical chromatogram of Flucytosine Standard 


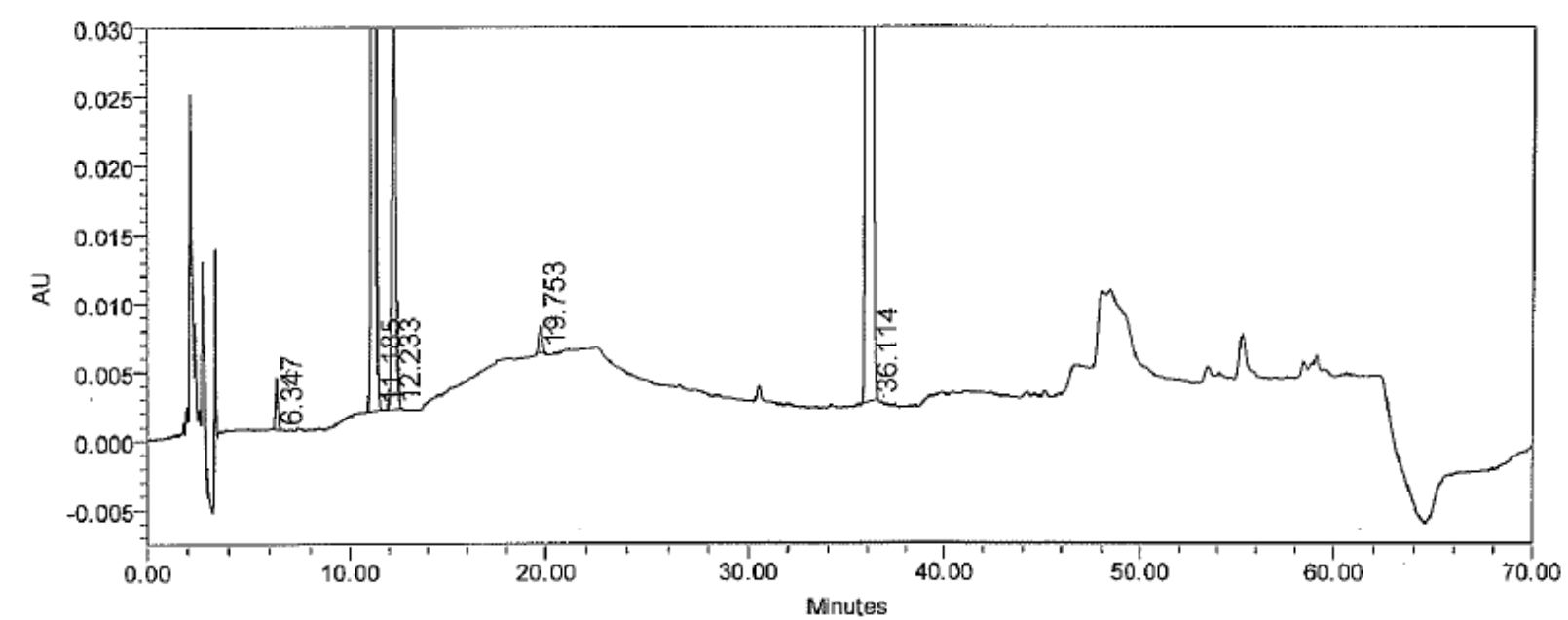

Figure 2. A typical chromatogram of Flucytosine Sample

Accuracy (Recovery test)

The accuracy of an analytical procedure expresses the closeness of agreement between the value, which is accepted either as a conventional true value or an accepted reference value and the value found. This is sometimes termed trueness.[21, 22] Accuracy, sometimes also referred to as recovery is an indicator of the trueness of the test measurements.[22] To determine the accuracy of the method three quality control samples were used. The samples chosen were such to represent the entire range of the standard curve i.e. lower, middle and higher concentration of the range.[23] The recovery experiments were carried out by the standard addition method. The recoveries obtained by the RP-HPLC method for Flucytosine are depicted in Table 5.

Table-5 Results of the recovery tests for the Flucytosine

\begin{tabular}{|c|c|c|c|}
\hline Level of Addition (\%) & Amount added (n=3) $\mathrm{ppm}$ & \% Recovery & \% Average recovery $\dagger$ \\
\hline 80 & 50 & 98.11 & 98.14 \\
\hline 100 & 100 & 99.22 & 99.44 \\
\hline 120 & 150 & 99.70 & 99.65 \\
\hline
\end{tabular}

\section{Calibration and linearity}

Linearity test solutions for the method were prepared from Acyclovir stock solutions at six concentrations levels from tested from $80 \%$ to $120 \%$ of the targeted level of the assay concentration Acyclovir. Standard solutions containing $80-120 \mu \mathrm{g} / \mathrm{ml}$ of Acyclovir in each linearity level were prepared. Linearity solutions were injected in triplicate. The calibration graphs were obtained by plotting peak area verses the concentration data was treated by least-squares linear regression analysis, the calibration graphs were found to be linear in the mentioned concentrations the slopes and correlation coefficients are shown in Table 6.

Table 6. Results of the LOD and LOQ

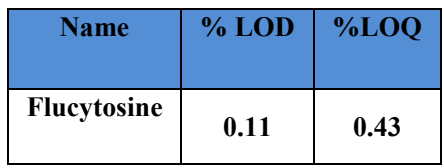

Figure 2. Linearity graph of Flucytosine 


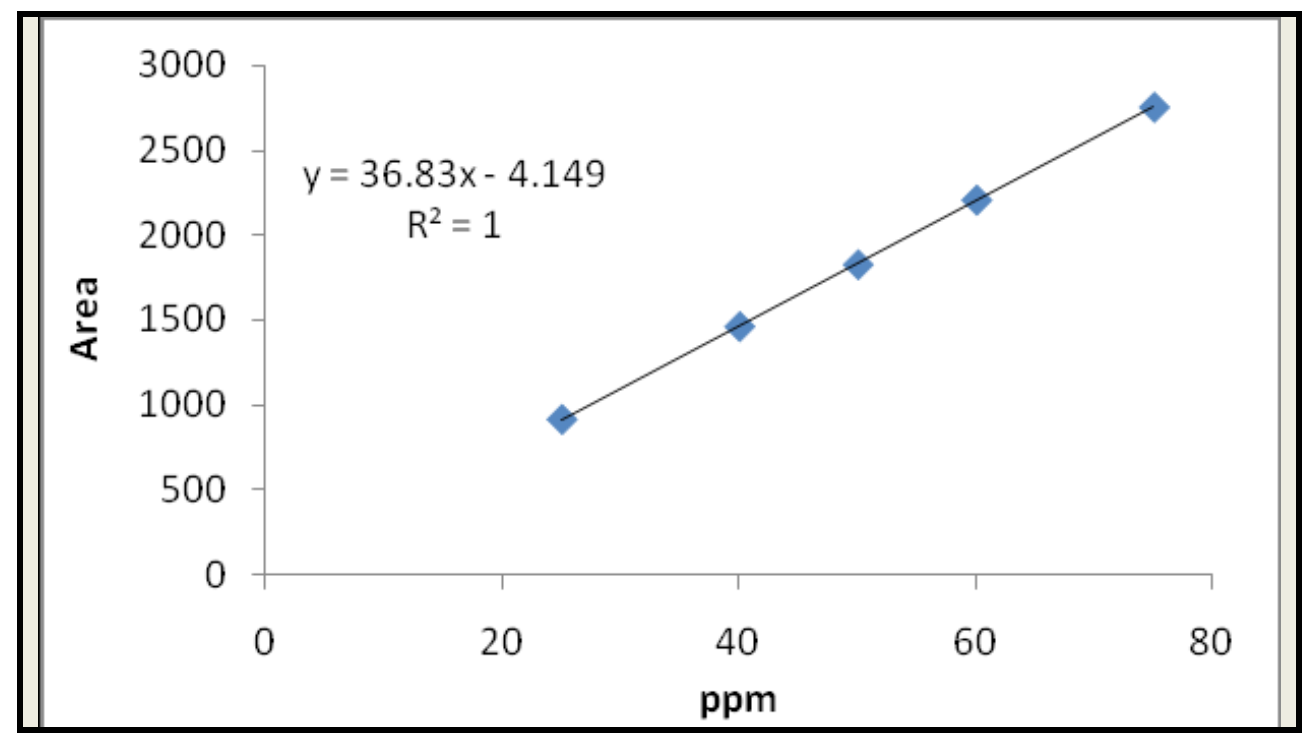

\section{Robustness}

To determine the robustness of the developed method experimental condition were purposely altered and the resolution between Flucytosin and acid degraded product were evaluated. The flow rate of the mobile phase was $1.0 \mathrm{ml} / \mathrm{min}$. To study the effect of flow rate on the resolution, it was changed by 0.2 units from 0.8 to $1.2 \mathrm{ml} / \mathrm{min}$ while the other mobile phase component was held as stated in chromatographic conditions. The effect of percent organic strength on resolution was studied by varying acetonitrile from -10 to $+10 \%$ while other mobile phase components were held constant as stated in chromatographic condition. The effect of column temperature on resolution was studied at 25 and $35 \mathrm{oC}$ instead of $30^{\circ} \mathrm{C}$ while the other mobile phase components were held constant stated in chromatographic condition. The results are shown in Table- 6

Table 6: Results of robustness study

\begin{tabular}{|c|c|c|c|}
\hline Sr. No. & \multirow{2}{*}{ Parameters } & Variations & Resolutions between Flucytosine and base degraded product \\
\hline \multirow{2}{*}{1} & \multirow{2}{*}{ Temperature } & $25^{\circ} \mathrm{C}$ & 8.22 \\
\cline { 3 - 4 } & & $35^{\circ} \mathrm{C}$ & 7.68 \\
\hline \multirow{2}{*}{2} & \multirow{3}{*}{ Flow rate } & $0.8 \mathrm{ml} / \mathrm{min}$ & 8.02 \\
\cline { 3 - 5 } & & $1.2 \mathrm{ml} / \mathrm{min}$ & 8.94 \\
\hline \multirow{2}{*}{3} & \multirow{2}{*}{ Mobile phase } & $40.5 \mathrm{ml}$ & 3.7 \\
\cline { 3 - 5 } & & $49.5 \mathrm{ml}$ & 3.3 \\
\hline
\end{tabular}

\section{LOD and LOQ (Sensitivity)}

A series of solutions in the range $0.2-1.1 \%$ of the assay concentration $(40 \mu \mathrm{g} \mathrm{mL}-1)$ were prepared by dilution of the standard solutions. Each solution $(20 \mu \mathrm{L})$ was injected five times, the areas were measured for the drug peak, and the standard deviation for the five injections was calculated for each concentration. On the basis of data obtained, the standard deviation at concentration 0 was calculated and this value was used for calculation of the LOD and LOQ.

\section{Stability of analytical solution}

The stability of the standard solutions and the sample solutions was tested at intervals of 24, 48 and $72 \mathrm{~h}$. The stability of solutions was determined by comparing results of the assay of the freshly prepared standard solutions. The RSD for the assay results determined up to $72 \mathrm{~h}$ for Flucytosin was $0.35 \%$. The assay values were within $+2 \%$ after $72 \mathrm{~h}$. The results indicate that the solutions were stable for $72 \mathrm{~h}$ at ambient temperature. 


\section{IV.CONCLUSION}

The method developed for quantitative determination of Flucytosin is rapid, precise, accurate and selective. The method was completely validated showing satisfactory data for all method-validated parameters tested. The developed method is stability indicating and can be used for assessing the stability of Flucytosin as bulk drugs. The developed method can be conveniently used for the assay determination of Flucytosin in bulk drugs and pharmaceutical dosage form.

\section{REFERENCES}

[1] Francis, P., Walsh, T., J. Clin. Infect. Dis. 1992, (15), 1003-1018.

[2] Benson, J., M, Nahata, M.C., Clin. Pharm. 1988, (7), 424-438.

[3] Polak, A., Scholer, H. J., Mode of action of 5-fluorocytosine, Rev Inst Pasteur Lyon, 1980, (13), 233-244.

[4] Scholer, H.J., Flucytosine In: Speller DCE, Antifungal Chemotherapy. New York: John Wiley \&Sons, 1980, 35-106.

[5] Vermes, A., van der Sijs, I.H., Guchelaar, H.J., Pharm World Sci. 1999, (21), 35-39.

[6] Waldorf, A.R., Polak, A., Antimicrob Agents Chemother, 1983, (23), 79-85. .

[7] Williams, K.M., Duffield, A.M., Christopher, R.K., Finlayson, O, J. Biomed Masss Spectrom, 1981 (8), 179-182.

[8] Washburn, R.G., Klym, D.M., Kroll, M.H., Bennett, J. E., J. Antimicrob Chemother, (1986), 17, 673-677.

[9] Yoshida, S., Adachi, T., Hirose, S. J. Chromatogr, 1988, (430), 156-162.

[10] Wintermeyer, S.M., Nahata, M.C., Am. J. Health Syst Pharm. 1996, (53), 7-9.

[11] Allen, L.V., Jr. Erickson, M.A., Am. J. Health-Syst Pharm. 1996, (53), 1944-1949.

[12] Germain, G., Lapierre, S., Tessier, D., Antimicrob Agents Chemotherr, 1989, (33), 1403-1405.

[13] Shostak, D., Klein, C., J. Assoc Off Anal Chem. 1986, (69), 835-836.

[14] Heather, L., Vandenbussche, Cary E Johnson, Jin Yun, Sima A Patel, Am. J Health Syst. Pharm. 2002, (59), 1853-1855.

[15] Yoshida, S., Adachi, T., Hirose, S. J. Chromatogr, 1988; 430: 156-162.

[16] Bergstrom, C.A., Norinder, U., Luthman, K., Artursson, Pharm Res, 2002, 19,182-188.

[17] Chaudhari, V., Ubale, M., Int. J. Analytical, Pharmacutical and Biomedical Sciences, 2012, (1), 2, 5-12. b) Ubale, M.B.; Dhakane, V.D.; Chaudhari, V.R. Applied Chemistry, 2011, (41), 5867-5870. c) Dhakane, V.D.; Ubale, M.B., A validated stability indicating HPLC assay method for buclizine hydrochloride in bulk drug and dosage form, Analytical Chemistry an Indian Journal, 2009, (8), 4, 602-607. d) Chaudhari, V. Ubale, M. International Journal of Advanceds in Pharmacy, Biology and Chemistry, 2012, (1), 3, 281-286. d) Ubale, M.B.; Bharad, J.V. Chaudhary, V.R. Journal of Current Chemical and Pharmaceutical Science, 2012, (2), 2, 107-112. e) Dhakane, V.D.; Ubale, M.B. International Journal of Chromatographic Science, 2012, (2), 3, 13-18. f) Chaudhari, V.; Ubale, M., A Research journal of Pharmaceutical, Biological and Chemical Science, 2012, (3), 3, 261-270.

[18] Bergstrom, CA; Norinder, U; Luthman, K and Artursson, Pharm Res, 2002, 19,182-188.

[19] Bergstrom, CA; Strafford, M; Lazorova, L; Avdeef, A; Luthman, K and Artursson, P. J Med Chem, 2003, (46), 558-570.

[20] Bergstrom, CA; Norinder, U; Luthman, K and Artursson, Pharm Res, 2002, (19), 182-188.

[21] Ozkan SA, Uslu B and Aboul-Enein HY, Crit Rev Anal Chem, 2003,(33), 155-181

[22] Hoetelmans R M, Profit M, Mennhorst P L, Mulder, J. Beijnen, J. H. J. Chromatogr B Biomed Sci Appl. , 1998,713,387

[23] Namita, K. Sateesh K and Ramesh P, Analytica Chimica Acta, 2002 466,175 